\title{
PERCEPÇÕES E DEMANDAS DE PROFESSORES SOBRE EDUCAÇÃO PREVENTIVA AO ABUSO DE ÁLCOOL E OUTRAS DROGAS
}

M. F. Knevitz, J. U. Béria, L. B. Schermann

Universidade Luterana do Brasil

marcosknevitz@hotmail.com

Submetido 31/07/2016 - Aceito 29/07/2017

DOI: $10.15628 /$ holos.2017.4901

\section{RESUMO}

Esta pesquisa visa aprofundar a compreensão sobre os aspectos da educação preventiva frente ao uso abusivo de substâncias psicoativas. Trata-se de um estudo exploratório, realizado com professores e gestores de escolas públicas, utilizando como instrumento o grupo focal. Os resultados apontam que as atividades ocorrem de modo incipiente e por iniciativas circunstanciais, sem uma linha clara para a prevenção. Os profissionais não se consideram suficientemente preparados para trabalhar com o tema. Além disso, as principais dificuldades relatadas são a formação insuficiente e a baixa participação da família. Logo, a educação preventiva deveria estar associada a uma proposta mais abrangente, em conformidade com a promoção da saúde e com ações integradas ao currículo escolar.

PALAVRAS-CHAVE: Instituições acadêmicas, Docentes, Transtornos relacionados ao uso de substâncias.

\section{PERCEPTIONS AND DEMANDS OF TEACHERS ON PREVENTIVE EDUCATION ABUSE OF ALCOHOL AND OTHER DRUGS}

\section{ABSTRACT}

This research aims to deepen the understanding of aspects of preventive education to the abuse of psychoactive substances. It is a exploratory study conducted with teachers and public school administrators, using as an instrument the focal group. The results show that the activities take place in an incipient way and circumstantial initiatives without a clear line for prevention. Professionals do not consider themselves sufficiently prepared to work with the theme. Besides the main difficulties are related to inadequate training and low family involvement. Therefore, the preventive education should be associated with a more comprehensive proposal in accordance with health promotion and integrated actions with the school curriculum.

KEYWORDS: Schools, Faculty, Substance related disorders. 


\section{INTRODUÇÃO}

Dados recentes acerca do uso mundial de drogas ilícitas mostram que no ano de 2013 o número de usuários chegou a um total de 246 milhões e estima-se que uma entre vinte pessoas, com idade entre 15 e 64 anos, tenha utilizado alguma substância psicoativa (SPA) ilícita no último ano. A magnitude da questão se torna mais evidente quando se considera que mais do que um dentre dez consumidores de drogas seja um usuário problemático, ou seja, que apresenta algum tipo de distúrbio devido a este uso. Além disso, apenas um a cada seis desses consumidores problemáticos tem acesso a algum tipo de tratamento (UNODC, 2015).

A consequência deste uso abusivo é o aumento na carga global de doença e anos de vida produtiva perdidos (Degenhardt et al, 2010), além de um número inaceitável de mortes relacionadas com drogas; sendo que cerca de 187100 pessoas perderam a vida prematuramente em 2013, em face do consumo dessas substâncias (UNODC, 2015). Acabar com a possibilidade do uso de drogas entre os seres humanos é tarefa muito difícil de ser alcançada, pois seria necessário modificar a própria condição ontológica do homem. Deste modo, as ações de prevenção ao uso abusivo de drogas deveriam estar voltadas para que o próprio sujeito pudesse ter condições de refletir e estabelecer uma melhor relação com as substâncias psicoativas (Sodelli, 2010).

Conforme o relatório do uso de drogas nas Américas (CICAD, 2015), o padrão atual do consumo de SPA estaria associado com a noção de facilidade ao acesso às drogas, a grande variedade das substâncias oferecidas e principalmente com uma percepção muito baixa do risco que o uso delas oferece. Isto, por sua vez, levanta questões sobre como devem ser desenvolvidas políticas públicas para prevenir o uso de drogas. No Brasil a gestão pública busca o enfrentamento deste problema por meio da elaboração de preceitos que orientem os envolvidos com a questão (Horta et al, 2014).

Neste processo a educação tem um papel fundamental, ao propiciar o estabelecimento de políticas de formação na área da prevenção do uso indevido de drogas para os professores e a implantação de projetos pedagógicos nas instituições de ensino, alinhados às diretrizes curriculares nacionais e aos conhecimentos relacionados a drogas (BRASIL, 2006).

Apesar das escolas terem sido apontadas como espaços privilegiados para o desenvolvimento de atividades preventivas e promotoras da saúde (Santos et al, 2011), existem dificuldades para atuar na educação preventiva ao abuso de álcool e outras drogas, pois os professores, mesmo reconhecendo seu papel de formadores de opinião, não se sentem motivados ou preparados para trabalhar com o tema (Araldi et al, 2012; Nascimento e De Micheli, 2015), o que leva ao prejuízo das ações (Al-Zboon, 2017).

Este estudo faz parte de uma pesquisa mais ampla, chamada "Educação preventiva ao uso abusivo de álcool e outras drogas, em escolas públicas, em um município da região metropolitana de Porto Alegre", que na sua parte quantitativa apontou para a necessidade das escolas em obter informações para trabalhar com o tema e para a formação insuficiente dos professores sobre o 
assunto (Knevitz, 2015). Sendo assim, esta pesquisa, de abordagem qualitativa, visa aprofundar a compreensão dos temas gerados na etapa quantitativa do estudo, pela elucidação dos seus significados.

\section{METODOLOGIA}

O grupo focal (GF) pode ser conceituado como uma entrevista com um grupo de pessoas sobre tópicos específicos, buscando coletar informações que possam propiciar a construção e compreensão de percepções, crenças e atitudes sobre temas, produtos e serviços. Sua especificidade está no fato de que se baseia na interação entre os participantes para obter os dados. Os resultados são produto de consenso do grupo (Minayo, 2010).

O GF foi realizado na sede da Secretaria Municipal de Ensino, em uma sala que permitiu conforto e privacidade, onde os componentes ficaram dispostos ao redor de uma mesa e tiveram sua comunicação oral registrada por dois gravadores. O grupo teve a participação de um moderador, um observador, seis participantes e duração de 102 minutos.

A escolha dos participantes foi intencional, tendo como critérios de inclusão, a participação na pesquisa quantitativa realizada anteriormente e o interesse pelo tema. Foram convidados seis professores e seis gestores das escolas pesquisadas, sendo que três gestores e três professores compareceram ao local na data definida. Os participantes do GF aceitaram participar do estudo, pela assinatura do Termo de Consentimento Livre e Esclarecido e foram identificados com o código alfanumérico, que significa pela ordem: o tipo de cargo que ele ocupa (G para gestor e $\mathrm{P}$ para professor) e numerado de 1 a 3.

O roteiro aplicado no GF utilizou como temas para a discussão, resultados encontrados no trabalho quantitativo, conforme o Quadro 1.

Quadro 1: Roteiro semiestruturado para a condução do grupo focal

\begin{tabular}{|c|c|}
\hline Assunto & Questões \\
\hline $\begin{array}{l}\text { Projeto Político Pedagógico e o tema } \\
\text { álcool e outras drogas }\end{array}$ & $\begin{array}{l}\text { - Como o Projeto Político Pedagógico trata do tema } \\
\text { álcool e outras drogas? } \\
\text { - Como são trabalhados os temas transversais? }\end{array}$ \\
\hline $\begin{array}{l}\text { Atividades desenvolvidas pela escola em } \\
\text { Educação Preventiva }\end{array}$ & $\begin{array}{l}\text { - Que tipo de atividades são realizadas na escola? } \\
\text { - Como o trabalho é conduzido? }\end{array}$ \\
\hline $\begin{array}{l}\text { Dificuldades da escola em implantar e } \\
\text { manter a Educação Preventiva }\end{array}$ & $\begin{array}{l}\text { - Quais as dificuldades encontradas para trabalhar } \\
\text { com Educação Preventiva? } \\
\text { - Como suplantar essas dificuldades? }\end{array}$ \\
\hline $\begin{array}{l}\text { Preparação dos docentes para trabalhar } \\
\text { com educação preventiva }\end{array}$ & $\begin{array}{l}\text { - Como é a formação do professor para trabalhar com } \\
\text { educação preventiva? } \\
\text { - O professor está preparado para a Educação } \\
\text { Preventiva? }\end{array}$ \\
\hline
\end{tabular}


As verbalizações do GF, depois de gravadas, foram transcritas de forma literal e analisadas através da técnica de análise de conteúdo (Minayo, 2010). Realizou-se a leitura exaustiva do material transcrito, seguida da ordenação e categorização em função da decorrência e destaque dos temas. Após a indexação do material, foi realizada a releitura de cada categoria e a construção de subtemas, que possibilitaram uma investigação mais específica sobre os assuntos, havendo consenso entre dois pesquisadores. Por fim, foi realizada a interpretação dos resultados e a comparação com o referencial teórico da pesquisa.

\section{RESULTADOS E DISCUSSÃO}

Das categorias definidas a priori, surgiram subcategorias emergidas das verbalizações ocorridas no grupo focal e que estão apresentadas no Quadro 2.

Quadro 2: Categorias e subcategorias do grupo focal

\begin{tabular}{|c|c|}
\hline Categorias & Subcategorias \\
\hline $\begin{array}{l}\text { Projeto Político Pedagógico e o tema álcool e } \\
\text { outras drogas }\end{array}$ & $\begin{array}{l}\text { Projeto pedagógico emergencial e não } \\
\text { preventivo } \\
\text { Temas transversais na sala de aula }\end{array}$ \\
\hline $\begin{array}{l}\text { Atividades desenvolvidas pela escola em } \\
\text { Educação Preventiva }\end{array}$ & $\begin{array}{l}\text { Atividades realizadas } \\
\text { Interatividade } \\
\text { Continuidade }\end{array}$ \\
\hline $\begin{array}{l}\text { Dificuldades da escola em implantar e manter a } \\
\text { Educação Preventiva }\end{array}$ & $\begin{array}{l}\text { Onde encontrar orientação sobre o tema } \\
\text { Participação inadequada da família } \\
\text { Obstáculos em participar da rede de } \\
\text { atendimento em saúde } \\
\text { Baixa participação dos professores }\end{array}$ \\
\hline $\begin{array}{l}\text { Preparação dos docentes para trabalhar com } \\
\text { educação preventiva }\end{array}$ & $\begin{array}{l}\text { Considerações sobre a base curricular } \\
\text { Atividades de formação inadequadas ou } \\
\text { insuficientes } \\
\text { Professores não se sentem preparados para a } \\
\text { educação preventiva }\end{array}$ \\
\hline
\end{tabular}

3.1. Projeto político pedagógico (PPP) e o tema álcool e outras drogas (AOD)

A lei brasileira sobre drogas (Lei n.11.343/2006) preconiza que as instituições de ensino implementem nos seus projetos pedagógicos, a prevenção ao uso indevido de AOD (Brasil, 2006). 
Apesar disso, os entrevistados admitiram que o tema era pouco abordado, sendo feito mais pela demanda da escola e menos como atividade preventiva, ou sequer era abordado por não estar no PPP.

\begin{abstract}
"Na rede municipal eu diria que tem ações nesta linha de prevenção, porém ainda de maneira bastante tímida. [...] eu vejo ainda somente como momentos que acontecem muito mais pela demanda. [...] pelo que a escola que esta demandando. A escola " $X$ " tem situação problema, situação conflito. Ai sim, temos uma intervenção. Não uma ação preventiva". (G1)

“Exato, ela (a prevenção) não tem uma orientação. Uma linha para se trabalhar, é muito mais isolado, por professores ou grupo de professores. [...] a própria gestão que tem uma linha de conduta, uma preocupação mais com a linha preventiva". (G1)
\end{abstract}

“No nosso PPP não tem nada específico que trate do assunto". (G3)

O Ministério da Educação normatiza o conteúdo curricular nos estabelecimentos de ensino através dos Parâmetros Curriculares Nacionais (PCNs). De acordo com essa legislação, os assuntos trabalhados nas escolas estão dispostos em dois grupos, sendo que no currículo tradicional são abrangidas as áreas de conhecimento e os temas transversais. Os temas transversais se referem a conteúdos de caráter social, que devem ser incluídos no currículo permeando as diferentes disciplinas da área de conhecimento, sem serem específicos a nenhuma delas. Conforme os PCNs, o tema AOD está dentro dos temas transversais referentes à saúde, devendo ser tratado nas dimensões individual e social, com os conteúdos organizados para o autoconhecimento e o autocuidado. Nesse sentido, as situações geradas pelo uso de AOD devem ser abordadas no tema vida coletiva e trabalhados em todas as áreas que compõem o currículo escolar de forma multidisciplinar (Brasil, 1998).

Apesar desta formalização, a realidade apresentada pelos professores do presente estudo mostra um envolvimento quase que exclusivo com os assuntos curriculares e pouca atenção voltada aos temas transversais gerais.

“Este negócio de prevenção é muito complicado [...] Porque cadaprofessor tem um plano que precisa seguir o ano inteiro, para dar conta [...] Chegando agora em novembro embola tudo porque começam as provas finais". (G3)

"Nós temos um prazo limite para encerrar todas as atividades e tu não vence tudo que tem que dar para os alunos". (G3)

“Os temas transversais geralmente estão mais a cargo do professor e são realizados como só dando uma passada, enquanto a preocupação maior é com o conteúdo (programático) em si". (P1)

Esta desvalorização dos temas transversais pelos professores igualmente foi observada no estudo de Marinho (2015) por meio do qual foi possível verificar as concepções de docentes sobre o tema transversal "Saúde" na cidade de Rio Grande-RS. Neste estudo, apesar de o tema transversal ser visto como conteúdo de ensino, ele foi, por sua vez, tratado como conhecimento 
periférico. Desse modo, pode-se identificar um conceito equivocado dos professores quando concebem os temas transversais como conteúdo adicional ao das disciplinas curriculares, cuja abordagem prejudicaria o cumprimento do conteúdo programático tradicional. Além disso, a noção de uma menor importância dos assuntos que estão fora do currículo formal, indica pouca apropriação dos temas transversais pelos professores. Destaca-se que a pouca valorização dos temas transversais também foi manifestada pelos participantes do presente estudo.

"O professor acha que é perda de tempo trabalhar temas transversais". (P2)

"É um tempo que vai faltar para trabalhar os assuntos do programa normal da escola". (P2)

"Como se aquele conteúdo, aquela fórmula de matemática, fosse mais importante que tratar sobre drogas, sobre sexualidade e sobre relações". (P2)

Outro ponto emergido das verbalizações e que aparece como empecilho para empregar o assunto AOD nos temas transversais, foi a falta de domínio em como tratar o assunto. $O$ professor atuaria com melhor desenvoltura nos conteúdos curriculares por estar melhor preparado tecnicamente. Esta mesma percepção foi manifestada por professores da cidade de São Paulo, SP (Ferreira et al, 2010).

"Quanto ao conteúdo programado de cada disciplina, apesar de existir esta correria para dar conta de tudo, o professor ainda se sente mais a vontade para trabalhar na sua disciplina, porque é a área de domínio dele". (P2)

A baixa participação dos professores nas atividades preventivas também emergiu das considerações dos professores do GF, como uma subcategoria importante, onde a tendência do profissional da educação era trabalhar com os assuntos que ele possui maior conhecimento, ou seja, onde ele foi preparado tecnicamente para atuar. O estudo de Araldi (2012), também aponta o desinteresse em intervir sobre as questões do tema AOD pela falta de preparo dos professores, enquanto Moreira (2015) menciona a falta de conhecimentos relacionados principalmente à multiplicidade de aspectos da relação do homem com as substâncias psicotrópicas como uma dificuldade para a atuação do professor nessa temática.

"Muitos professores encaram como um trabalho a mais [...] não é visto como uma coisa que será boa para o aluno e para ele mesmo, pois vai ter que correr atrás". (P2)

"[...] mas eu vejo assim, se tu faz uma reunião com proposta de tratar de temas ou conteúdos que já estão colocados no plano de estudos, de cada série, o professor se acha a vontade para trabalhar". (P2)

"Inclusive, com certeza, pelo menos na minha escola, não conseguiremos abranger todos os profissionais". (P3)

"Vamos abranger apenas um certo percentual de pessoas (professores)". (G3) 
O comodismo dos professores em relação à capacitação para assuntos que não dominam, dentre os quais o tema AOD, foi outro resultado obtido por meio deste estudo. Isto gera uma dificuldade adicional para a implantação da educação preventiva. Este resultado vai ao encontro de outros estudos que também observaram relação entre a baixa apropriação dos temas transversais (Marinho, Silva e Ferreira, 2015) bem como com a ausência da vivência prática dos professores sobre o tema (Moreira, Vóvio e De Micheli, 2015).

\begin{abstract}
"No momento que tu começas a trabalhar os temas transversais, que tu, como professor, te dá conta que não está preparado para aquele assunto, para passar para o aluno e que vai te dar um pouco de trabalho, porque tu vai ter que conhecer primeiro, tu vai ter que estudar, pesquisar pra ti conseguir orientar o aluno ocorre uma barreira, do comodismo". (P2)

"É mais fácil eu não tocar neste assunto e seguir com o conteúdo normal programado, que já está no meu plano de estudos, do que eu parar para fazer uma roda de conversa, para fazer um diálogo sobre o assunto". (P2)
\end{abstract}

\title{
3.2. Atividades desenvolvidas pela escola em Educação Preventiva
}

No que diz respeito às atividades desenvolvidas em educação preventiva, as palestras apareceram como as ações específicas mais realizadas nos estabelecimentos de ensino. Esse resultado corrobora a pesquisa quantitativa, onde este tipo de atividade foi responsável por 26,5\% das ações em prevenção nas escolas estudadas (Knevitz, 2015).

"Nós, como escola, temos feito algumas atividades que envolvam este assunto, como palestras sobre o tema". (G3)

"Foi trabalhado o assunto com palestras específicas, sempre focadas para determinadas idades, mais para o ensino fundamental". (G3)

Cabe salientar que a palestra é um tipo de atividade que implica em uma interatividade pequena com os alunos e, portanto, implica em pouca efetividade quando utilizada de forma isolada (Barbosa, Pereira e Oliveira, 2014). A preocupação com ações de maior participação coletiva para uma maior efetividade também foi mencionada pelos participantes do presente estudo.

"Fiz um trabalho com os alunos, que foi bem legal. Eu perguntei: quais os caminhos de quem opta pela droga? Pedi que pesquisassem vídeos que mostrassem estes caminhos. Ou mesmo (podiam) dramatizar. Eles trouxeram coisas muito boas, muito legais". (P1)

"Onde eles participam, onde eles se colocam e são os autores, temos resultados muito legais"... (P1)

"Eu acho que os alunos vão aprender mais com um tipo de trabalho onde eles vão tirar suas próprias conclusões". (P3)

"É melhor (o resultado) de um trabalho que eles mesmo desenvolveram, do que quando alguém chega e diz para eles: isto é ruim e tu não deve fazer. É um trabalho mais interativo". (P3) 
A continuidade das ações apareceu nas verbalizações do GF como um aspecto importante das ações de prevenção na escola. Conforme Barbosa (2014), a continuidade é característica essencial dos projetos mais efetivos em educação preventiva ao uso abusivo de drogas, pois possibilita acompanhar o desenvolvimento das ações e apresentar estratégias longitudinais.

"E tem que haver uma continuidade, porque da maneira que as coisas estão ocorrendo, com uma palestra aqui, outra atividade lá, passa o tempo [...] não leva a nada". (P2)

"Tu tens um despertar, mas isto acaba morrendo logo ali, na praia, porque não houve um aprofundamento. Perde-se o objetivo, perde-se o estímulo". (P2)

\subsection{Dificuldades da escola em implementar e manter a Educação Preventiva}

A preocupação em procurar profissionais com conhecimento sobre o assunto AOD, para orientar como proceder junto aos alunos, foi mencionada de forma enfática no GF. Isso parece ser uma tendência já demonstrada em outros estudos (Ferreira et al, 2010; Araldi et al, 2012; Nascimento e De Michelli, 2015), segundo os quais as instituições de ensino têm procurado por especialistas visando orientação ou mesmo com a finalidade de delegar esta tarefa (Nascimento e De Michelli, 2015).

"Está lá no meu plano de ação do SOE (serviço de orientação educacional), eu tenho que fazer alguma coisa, mas sozinho é complicado" (P1)

"A gente teria que contar com especialistas para nos orientar". (P1)

"Eu acho que localizar pessoas que realmente tenham formação e tragam material próprio para a clientela que a gente tem é o primeiro ponto". (G3)

"Tu esbarra em onde tu vai conseguir, com quem tu vai falar, quem trabalha com isto". (G3)

No entanto, em situações emergenciais, as orientações buscadas fora do âmbito escolar nem sempre contemplam as necessidades específicas da situação apresentada. A fala mencionada a seguir, exemplifica uma situação emergencial de apreensão de um aluno com drogas dentro da escola.

Esse tipo de dificuldade pode ser exemplificada pela fala apresentada a seguir, onde, após um aluno ser apreendido com drogas dentro da escola, os gestores tiveram uma orientação surpreendente e negativa.

"Nós fomos atrás, pedimos socorro, nós falamos: estamos precisando, o menino está com problema, a família está com problema. Nós precisamos de ajuda. (G2)

"Ninguém ajudou. Eles não sabiam o que fazer. Nos encaminharam para o jurídico da CRE (Coordenadoria Regional de Educação). O que o jurídico vai me dizer"? (G2) 
Essa situação prática na rotina de uma escola, teve um encaminhamento que não procurou a resolução do problema relacionado ao uso de drogas, mas sim apenas proteger a instituição de alguma questão jurídica que pudesse surgir do incidente. $\mathrm{O}$ aluno, como indivíduo com necessidade premente de ser atendido pela rede de saúde especializada, não foi contemplado pelos gestores regionais de educação. A fragilidade da comunicação entre as redes de atenção aos usuários, as escolas e os órgãos governamentais, demonstra que existem poucas estratégias sistematizadas de prevenção, já mencionadas inclusive por Araldi (2012).

Outro fator de grande relevância na dificuldade da implantação da educação preventiva nas escolas, que apareceu com destaque nas verbalizações dos componentes do GF, foi a baixa participação da família nas atividades. Essa constatação também foi identificada no estudo de Araldi (2012), quando pesquisou-se acerca das representações sociais de professores no interior de Santa Catarina, assim como no estudo de Knevitz (2015) o qual investigou as práticas docentes em educação preventiva ao abuso de AOD, de forma quantitativa, no interior do Rio Grande do Sul.

A Pesquisa Nacional de Saúde do Escolar (PeNSE, 2012) (Horta et al, 2014), corrobora os resultados destas pesquisas, por encontrar uma associação entre o uso de drogas ilícitas e o contato insuficiente entre a escola e os pais.

"O trabalho preventivo na escola parte da orientação educacional, mais a supervisão e a direção, embora o entrave maior esteja na questão dos pais. A gente já fez aqueles chamamentos, trazemos palestrantes, os pais não vão, não valorizam a escola em si". (P1)

"Somos esta mesa com quatro pernas, mas quando chega na da família, está quebrada". (P1)

"Nós vemos que os pais, lá na educação infantil, na formatura do pré, aquela coisa toda, até o 4으, 5으 ano eles acompanham. Depois entra na préadolescência, que a gente quer, então, que os pais venham para trabalhar esta questão da pré-adolescência, da adolescência, onde mais eles precisam deste manejo com o aluno, eles somem da escola". (P1)

A transferência de responsabilidades por parte dos pais para a escola também foi enfatizada como sendo um fator de dificuldade de relacionamento entre estes dois atores do processo de prevenção.

\footnotetext{
"A família quer passar a responsabilidade, que a gente resolva. Querem transferir para a escola um problema estrutural familiar, que a gente não tem condições de resolver. [...] a gente já está vendo desde cedo esta falta da família presente na vida de cada criança. Na vida do seu filho". (P2)

"O que eu noto é que é muito fácil tu entregar para um professor, tu exigir que um professor transmita um conteúdo, ensine valores, ensine comouma criança se comportar [...] valores comportamentais, né, que a família não tem mais hoje". (P2)
} 
Além disso, na questão do uso indevido de drogas, os professores relataram que dentro da família, também existe uma dificuldade dos pais observarem que seus filhos estão com um comportamento diferente. Muitos pais não acreditam que seu filho está fazendo uso de drogas e quando a escola faz contato e coloca a situação, o sentimento é de surpresa e negação.

"O pai não vai saber se o filho vai usar e mesmo quando usa, ele nem se dá conta das transformações na vida do filho. Nós, na escola, observamos pelo fato de estarmos no dia a dia com a criança". (P2)

"Não existe conversa na família, ou prevenção". (G2)

"Meu filho nunca vai fazer isto. Meu filho não faz isto. Nos momentos que tivemos na escola, quando tu comunica o pai sobre o problema, que o seu filho está fora de si na sala de aula, é um baque que ele leva". (P3)

"Eu acho que o pai leva aquele baque porque ele pensa que com filho dele não vai acontecer [...] Dificilmente os pais tem a noção que seu filho está correndo risco. Que tem que alertar ele ou a escola sobre isto". (P3)

As verbalizações emergidas do GF indicaram também as dificuldades em participar da rede de atendimento em saúde. Quando ocorrem problemas com SPAs no ambiente escolar, onde existe a necessidade de atendimento dos estudantes por profissionais da saúde, o encaminhamento das questões esbarra na fragilidade da rede de apoio. Na pesquisa-ação de Moreira (2015), que investigou os fatores com potencial para dificultar a realização de ações preventivas nas escolas, foi também descrito esse aspecto do processo como um obstáculo a ser superado.

\footnotetext{
"Nós, como escola, não temos subsídios no local, uma pessoa específica [...] que diga: olha tu vai procurar tal pessoa". (G3)

"Só na escola a gente não consegue fazer tudo o que é necessário. Na nossa escola procuramos encaminhar para o CAPS (centro de atendimento psicossocial), mas é difícil". (P1)

"As vezes, demora e as famílias não têm condições de buscar, por si só, o atendimento. [...] É um processo demorado e muitas vezes, quando chega a ser atendido, a situação se agravou bastante [...]Tem casos bem complicados onde se fazem necessárias outras atitudes como entrar no fórum e até buscar internação". (P1)
}

\subsection{Preparação dos docentes para trabalhar com educação preventiva}

Nas pesquisas sobre a educação preventiva ao uso indevido de álcool e outras drogas no ambiente escolar, tanto a nível nacional (Nascimento e De Michelli, 2015), quanto fora do Brasil (Norberg, Kezelman e Lim-Hove, 2013), a importância do professor como o principal ator deste processo é destacada como um dos maiores pilares de efetividade das ações. Apesar disso, os resultados desta pesquisa demonstram que as atividades de formação na área da prevenção estão sendo insuficientes para que o profissional da educação se sinta capacitado para exercer seu papel. Considerações sobre a base curricular do professor, advindas das verbalizações, 
demonstram a preocupação em modernizar a base curricular, para uma melhor atuação, não só no tema drogas, mas também em outros aspectos da vida contemporânea.

"Quando se fala da formação do professor, a coisa está um pouco complicada". (G1)

“O nosso currículo é o mesmo currículo que formou pessoas há muito tempo atrás. Mudanças são bem vindas. A escola não está preparada não só para prevenção, mas para dar conta desta diversidade toda". (G1)

Com relação às atividades de formação específica sobre prevenção ao abuso de drogas, os componentes do grupo relataram que estas eram inadequadas ou insuficientes para a capacitação dos profissionais da educação, o que confirma os resultados de estudos nos quais os professores relataram não estarem capacitados suficientemente para transmitir informações aos alunos, apesar de participar de algum tipo de evento relacionado ao tema (Ferreira et al, 2010; Knevitz, 2015).

"Acredito que as pessoas que responderam que já participaram de formação em educação preventiva foram as que participaram das palestras que tiveram nas escolas. Atividades mais simples e de curta duração. Não um curso". (G1)

"Eu acho que um encontro, uma palestra,não te forma pra nada. Me desculpe, mas eu vou lá receber um monte de informação, que não consigo assimilar totalmente". (G3)

Além disso, apontaram a falta de incentivo de formação técnica sobre o assunto, por parte da administração pública, como uma dificuldade importante.

"Os cursos de formação que nos são enviados, são visando avaliação de alunos, visando PPP da escola, alguns projetos, mas visando mais a parte pedagógica, não temas transversais". (G2)

"De minha parte eu nunca tive atividade específica no assunto".(G3)

“Oficialmente não nos ofereceram nada (em prevenção)". (G3)

As verbalizações apresentadas nesta pesquisa revelaram ainda que, principalmente devido a falta de instrução sobre o tema relacionado ao uso abusivo das substâncias psicoativas, os professores não se sentem preparados para atuar na educação preventiva.

"Temos dificuldade com o tema, eu acho [...] porque nós não temos uma formação para conseguir falar disto. Nós como gestores ou mesmo professores não temos este conhecimento, mesmo, para tratar disto". (G3)

"[...] quando enfrentamos uma situação prática na escola, nos sentimos mais leigas e até mais fora da realidade, que os nossos alunos". (P2)

"Não tem modelo (preventivo) nenhum, [...] geralmente (o assunto) fica solto. A maioria dos professores tem muitas dúvidas". (G2)

Os resultados deste estudo corroboram, portanto, os achados de outras pesquisas sobre as representações dos professores acerca da prevenção na escola (Araldi et al, 2012; Nascimento 
e De Michelli, 2015), que têm referenciado dificuldade dos profissionais da educação em trabalhar com o tema por não se sentirem preparados. Fora isso, apenas $24 \%$ dos docentes do estudo de Knevitz (2015) se declararam aptos a realizar atividades preventivas.

\section{CONSIDERAÇÕES FINAIS}

Os resultados dessa pesquisa indicam que a educação preventiva ao uso abusivo de SPAs no ambiente escolar estudado, não está ocorrendo de forma sistemática. Praticamente não existem atividades realizadas com planejamento e abrangência necessárias para atingir resultados minimamente satisfatórios. Parece não haver, nas escolas, tanto a nível municipal quanto estadual, uma linha clara e definida para a prevenção. As poucas práticas relatadas são provenientes de iniciativas circunstanciais e individuais, sem continuidade das ações.

A educação preventiva deveria estar associada a uma proposta mais abrangente e em conformidade com a promoção da saúde. Desse modo, contando com ações integradas ao currículo escolar (Fletcher, Bonell e Sorhaindo, 2010) e tendo a redução de danos como delineamento das ações, pela efetividade comprovada (Midford et al, 2012), diminuição da estigmatização e da discriminação dos usuários (Vázquez, 2014), consequentemente será maior a probabilidade em proporcionar ao aluno, melhor capacidade de discernimento quanto ao uso de SPAs.

Os achados deste trabalho demonstraram ainda que a formação dos professores carece de um maior investimento por parte dos gestores da educação, de modo a proporcionar condições técnicas que permitirão o desenvolvimento de ações com metodologia adequada à prevenção. Dentre essas condições, é preciso ressaltar que esta formação teórica do professor deveria estar agregada a melhores condições para exercer suas atividades, de modo que salário, jornada de trabalho e condições estruturais dos estabelecimentos de ensino são questões fundamentais do processo.

\section{REFERÊNCIAS}

Al-Zboon, E. (2017) Combating substance misuse: competences and preparation of special education department students. Substance Abuse Treatment, Prevention, and Policy, 12(1), 16.

Barbosa, A. J. G; Pereira, C, E, S; Oliveira, J, C. (2014). Prevenção ao uso de drogas por adolescentes: intervenções que funcionam. In: Ronzani, T, M; Silveira, P, S (org.). Prevenção ao uso de álcool e outras drogas no contexto escolar. Observatório Brasileiro de Informações sobre Drogas - OBID. Juiz de Fora: ed. UFJF. 
Brasil. (2015). Ministério da Educação. Parâmetros Curriculares Nacionais -Temas Transversais em Saúde. Brasília. MEC, 1998. Disponível em: http://portal.mec.gov.br/seb/arquivos/pdf/saude.pdf. Acesso em 01 set. 2015.

Brasil. (2015). Lei n.11343, de 23 de agosto de 2006. Institui o Sistema Nacional de Políticas Públicas sobre Drogas - SISNAD; Prescreve medidas para prevenção do uso indevido, atenção e reinserção social de usuários e dependentes de drogas; Estabelece normas para repressão à produção não autorizada e ao tráfico ilícito de drogas; Define crimes e dá outras providências. Diário Oficial da União, Brasília, DF, 2006. Disponível em: <http://www.planalto.gov.br/ccivil_ 03/_ato2004-2006/2006/lei/l11343.htm> Acesso em: 13 ago. 2015.

Comisión Interamericana para el Control del Abuso de Drogas (CICAD). (2015). Informe del Uso de Drogas en las Américas, 2015.2 Disponível em: <http://www.cicad.oas.org/apps/document.aspx?id=3209> Acesso em 20 out. 2015.

Degenhardt, L. et al. (2013). Global burden of disease attributable to illicit drug use and dependence: findings from the global burden of disease study 2010. Lancet, 382, 1564-74.

Ferreira, T. C. D. et al. (2010). Percepções e atitudes de professores de escolas públicas e privadas perante o tema drogas. Rev. Interface - Comunicação, Saúde, Educação, 14(34), 551562.

Fletcher, A; Bonell, C; Sorhaindo A. (2010). "We don't have no drugs education": the myth of universal drugs education in english secondary schools? International journal of drug policy, 21, 452-458.

Horta, R. L. et al. (2014). Uso na vida de substâncias ilícitas e fatores associados entre escolares brasileiros, Pesquisa Nacional de Saúde do Escolar (PeNSE, 2012). Rev. Bras. Epidem. (Suppl. PeNSE), 31-45.

Knevitz, M. F. (2015) Educação preventiva ao abuso de álcool e outras drogas, em escolas públicas, em um município da região metropolitana de porto alegre (Dissertação de mestrado). Universidade Luterana do Brasil - ULBRA, Canoas, RS, Brasil.

Marinho, J. C. B; Silva, J. A; Ferreira, M. (2015). A educação em saúde como proposta transversal: analisando os parâmetros curriculares nacionais e algumas concepções docentes. História, Ciências, Saúde, 22(2), 429-443.

Midford R. et al. (2012). Drug education in victorian schools (DEVS): the study protocol for a harm reduction focused school drug education trial. BMC public health, 12:112.

Minayo, M. C. S. (2010). O desafio do conhecimento: pesquisa qualitativa em saúde. (12a ed.) São Paulo (SP): Hucitec.

Moreira, A; Vovio, C. L; De Micheli, D. (2015). Prevenção ao consumo abusivo de drogas na escola: desafios e possibilidades para a atuação do educador. Educ. Pesquisa, 41(1), 119-135. 
Nascimento, M. Oliveira; De Micheli, D. (2015). Avaliação de diferentes modalidades de ações preventivas na redução do consumo de substâncias psicotrópicas em estudantes no ambiente escolar: um estudo randomizado. Rev. Ciência Saúde Coletiva, 20(8),2499-2510.

Norberg, M; Kezelman, S; Lim-Howe, N. (2013). Primary prevention of cannabis use: a systematic review of randomized controlled trials. Plos One Journal.Pone, 8(1), jan.

Santos, E. O. et al. (2011). Abordagem sobre a prevenção de drogas no contexto escolar. Rev. Cient. Internacional, 4(17), 18-40.

Sodelli, M. (2010). A abordagem proibicionista em desconstrução: compreensão fenomenológica existencial do uso de drogas. Rev. Ciência Saúde Coletiva, 15(3), 637-44.

United Nations Office on Drugs and Crime (UNODC). (2015) World Drug Report: executive summary. Viena, 2015. Disponível em: <http://www.unodc.org/documents/wdr2015/world_drug_report_2015.pdf> acesso em: 25 set. 2015.

Vázquez, A. (2014). Políticas públicas en materia de drogas en argentina: políticas de estigmatización y sufrimiento. Saúde Debate, 38(103), 830-839. 